\title{
Efeito de óxidos de níquel na sinterização de nanopartículas de óxido de cério dopado com samário (SDC) para aplicação em pilhas a combustível
}

\author{
The effect of nickel oxide on the sintering of \\ nanoparticles of samarium doped cerium \\ oxide (SDC) for application in fuel cells
}

\author{
Fernanda Regina Rocha Caldas ${ }^{1}$, Julliana de Oliveira Guimarães ${ }^{1}$, \\ Marta Eloísa Medeiros ${ }^{1}$, Francisco Manoel dos Santos Garrido ${ }^{1}$
}

\begin{abstract}
${ }^{1}$ Laboratório de Química de Materiais Avançados - Instituto de Química/UFRJ. Av. Athos da Silveira Ramos, 19, Centro de Tecnologia, Bloco A, sala 632. CEP 21949-909, Cidade Universitária, Rio de Janeiro, RJ, Brasil. e-mail: fernandacaldas@oi.com.br, martan@iq.ufrj.br, chico@iq.ufrj.br
\end{abstract}

\begin{abstract}
RESUMO
As pilhas a combustível permitem a geração de energia elétrica de forma limpa e eficiente. Dentre seus diferentes tipos destaca-se a pilha a combustível do tipo óxido sólido (PaCOS). O óxido de cério dopado com samário (SDC) tem sido amplamente estudado, visando sua aplicação como eletrólito sólido e na elaboração do anodo tipo cermet. Inicialmente, este trabalho descreve a síntese, através do método do precursor, de nanopartículas de óxido de cério dopado com $20 \%$ mol de samário $\left(\mathrm{Ce}_{0,8} \mathrm{Sm}_{0,2} \mathrm{O}_{1,9}\right)$. Posteriormente, é analisado o efeito do óxido de níquel $(\mathrm{NiO})$ e do óxido de níquel dopado com $10 \%$ de cobalto $(\mathrm{CoNiO})$ na sinterização de pastilhas de SDC, a $1200{ }^{\circ} \mathrm{C}$, visando à obtenção de porcentuais de sinterização superiores a $90 \%$. Os materiais foram caracterizados por Difração de Raios X (DRX), Espectroscopia do Infravermelho (IV), Análise Térmica (TG/DTA), Microscopia Eletrônica de Transmissão (MET) e Espectroscopia Raman. Observou-se um aumento no percentual de sinterização de 83,1 \% (pastilha de SDC pura) para 98,6\% (pastilha de SDC com CoNiO). Portanto, a SDC preparada pelo método do precussor permite a obtenção de pastilhas com alta densificação, o qual é um dos pré-requisitos para sua utilização na elaboração de componentes de pilhas a combustível do tipo PaCOS.
\end{abstract}

Palavras-chave: PaCOS, eletrólito sólido, óxido de cério dopado com samário, SDC.

\begin{abstract}
Fuel cells allow generation of electric energy in a clean and efficient way. Among the different types of fuel cells, solid oxide fuel cell (SOFC) stands out. Samarium doped cerium oxide (SDC) have been widely studied for its application as solid electrolyte and as a component of cermet type anode. Initially, this work describes synthesis of nanoparticles of $20 \%$ mol samarium doped cerium oxide $\left(\mathrm{Ce}_{0,8} \mathrm{Sm}_{0,2} \mathrm{O}_{1,9}\right)$, by the precursor method. Subsequently, we analyze the effect of nickel oxide (NiO) and $10 \%$ cobalt-doped nickel oxide $(\mathrm{CoNiO})$ on the sintering at $1200{ }^{\circ} \mathrm{C}$ of SDC pellets, aiming to attaining a sintering degree higher than $90 \%$. Materials were characterized by X-ray Diffraction (XRD), Infrared Spectroscopy (IR), Thermal Analysis (TG/DTA), Transmition Electron Microscopy (TEM) and Raman Spectroscopy. We observed an increase in percentage of sintering from $83.1 \%$ (pure SDC pellet) to $98.6 \%$ (SDC pellet with CoNiO). Therefore, SDC prepared by the precursor method allows obtaining pellets with high density, which is a prerequisite for their use in preparation of components of SOFC type fuel cells.
\end{abstract}

Keywords: Solid oxide fuel cell, solid electrolyte, SOFC, Samarium doped cerium oxide, SDC.

\section{INTRODUÇÃO}


Pilha a combustível é um dispositivo eletroquímico que realiza a conversão de energia gerada por uma reação química em energia elétrica, sendo um método limpo e altamente eficiente de geração de eletricidade e calor [1-15]. Esses dispositivos, de geração de energia, apresentam vantagens frente a outros, além disso, os produtos gerados no seu funcionamento são menos poluentes. Dentre os diversos tipos de pilhas a combustível, destaca-se a pilha a combustível de óxido sólido (PaCOS). No entanto, a alta temperatura de operação de uma pilha a combustível do tipo PaCOS, entre $800-1000{ }^{\circ} \mathrm{C}$, dificulta seu emprego. Um aspecto abordado atualmente, consiste na diminuição da temperatura de operação da PaCOS proporcionando uma maior flexibilidade na escolha de materiais para montagem da pilha a combustível, o que diminuiria seu custo total [716]. O eletrólito sólido e o anodo do tipo cermet são componentes fundamentais de uma pilha a combustível do tipo PaCOS, nesses dois componentes a condutividade iônica é um dos parâmetro limitantes para a diminuição da temperatura de operação de uma pilha a combustível do tipo PaCOS. Sendo que, este parâmetro é fortemente dependente do tipo de condutor iônico utilizado e da qualidade de sua sinterização [6-14].

Eletrólitos cerâmicos baseados em óxido de cério $\left(\mathrm{CeO}_{2}\right)$ têm sido amplamente estudados [1, $\left.\underline{6}-27\right]$. O $\mathrm{CeO}_{2}$ puro é um mau condutor iônico $\left(\sigma_{700^{\circ} \mathrm{C}}=1,9 \times 10^{-5} \mathrm{~S} / \mathrm{cm}\right)$, no entanto, sua condutividade iônica a $700{ }^{\circ} \mathrm{C}$ aumenta com a substituição de $\mathrm{Ce}^{4+}$ por íons metálicos de menor valência, sendo os mais empregados o $\mathrm{Sm}^{3+}\left(\sigma_{700^{\circ} \mathrm{C}}=1,8 \times 10^{-2} \mathrm{~S} / \mathrm{cm}\right)$ e o $\mathrm{Gd}^{3+}\left(\sigma_{700^{\circ} \mathrm{C}}=3,7 \times 10^{-2} \mathrm{~S} / \mathrm{cm}\right)[1, \underline{7}-\underline{30}]$. Os óxidos de cério dopado com samário (SDC) são altamente refratários, portanto, sinterizar esses materiais é uma tarefa desafiadora. As altas temperaturas utilizadas na sua sinterização, por volta de 1400 e $1600{ }^{\circ} \mathrm{C}$, podem causar redução do $\mathrm{Ce}^{4+}$

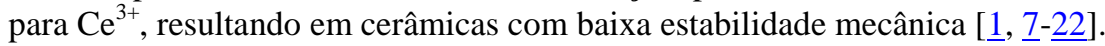

Com relação ao anodo, temos que a atmosfera redutora utilizada na pilha a combustível do tipo PaCOS permite o uso de um metal como o níquel. O níquel tem como vantagem um menor custo comparado com os outros metais e como desvantagem a característica de sinterizar na temperatura de operação da pilha a combustível, resultando em uma diminuição na porosidade do eletrodo. Esse problema pode ser evitado com a obtenção de um esqueleto poroso, formado por um eletrólito cerâmico, no qual são dispersas as partículas de níquel, formando um cermet [ 5-7, 14-17]. Este tipo de abordagem impede a sinterização do níquel, mantém a porosidade do anodo e aumenta a adesão entre eletrodo/eletrólito, garantindo uma interface com maior aderência mecânica e condutividade elétrica. $\mathrm{O}$ anodo do tipo cermet é fabricado com uma porosidade de $20 \mathrm{a}$ $40 \%$ e precisa apresentar uma boa estabilidade mecânica e ser um condutor eletrônico estável em ambiente redutor. Sendo que, deve possuir porosidade suficiente para permitir o transporte do combustível até a interface eletrólito/eletrodo e dos produtos da oxidação do combustível para fora do eletrodo [ $[\underline{6}, 7]$.

Os cermets formados pelos eletrólitos de céria dopada (SDC), juntamente com o metal níquel, tem sido intensamente estudados e espera-se que estes cermets permitam uma diminuição da temperatura de operação da pilha a combustível do tipo PaCOS $[\underline{6}, \underline{14}-\underline{17}]$. Ao adicionarmos ao cermet de Ni/SDC outro metal, como o cobalto, por exemplo, formando o cermet de $\mathrm{CoNi} / \mathrm{SDC}$, a condutividade eletrônica do anodo aumenta. Além disso, o cobalto age como um "catalisador" facilitando a oxidação do combustível [ㄱ, 24].

Este trabalho descreve a síntese de nanopartículas do dióxido de cério dopado com samário (SDC), com substituição de $20 \%$ mol de samário $\left(\mathrm{Ce}_{0,8} \mathrm{Sm}_{0,2} \mathrm{O}_{1,9}\right)$, para futura aplicação como eletrólito de uma pilha a combustível do tipo PaCOS. Visando a preparação dos cermets, foi feita a síntese do óxido de níquel e do óxido de níquel dopado com cobalto, assim como, foi avaliado o efeito da adição desses óxidos na sinterização de pastilhas de SDC. Para diminuir a possibilidade de redução do $\mathrm{Ce}^{4+}$ para $\mathrm{Ce}^{3+}$ a sinterização foi realizada na temperatura de $1200{ }^{\circ} \mathrm{C}$.

\section{MATERIAIS E MÉTODOS}

As sínteses descritas a seguir foram realizadas a partir de reagentes com grau de pureza P.A. Para melhor entendimento dos materiais estudados será adotada a seguinte denominação: material/temperatura de calcinação em ${ }^{\circ} \mathrm{C}$. Enquanto que, para as pastilhas sinterizadas: material/temperatura de calcinação em ${ }^{\circ} \mathrm{C} /$ temperatura de sinterização em ${ }^{\circ} \mathrm{C}$.

\subsection{Obtenção de nanopartículas de SDC}

Na preparação de nanopartículas do precursor oxihidroxicarbonato de cério e samário (SDC/50) foi utilizada uma modificação do método proposto por Li e colaboradores [20]. Este método permite a obtenção de pós reativos e com baixa concentração de $\mathrm{Ce}^{3+}[20, \underline{31}]$. Foi preparada uma solução aquosa de nitrato de cério IV e amônio $\left(\mathrm{NH}_{4}\right)_{2} \mathrm{Ce}\left(\mathrm{NO}_{3}\right)_{6}$ (VETEC), o óxido de samário $\left(\mathrm{Sm}_{2} \mathrm{O}_{3}\right)$, fornecido pelo Instituto de Engenharia Nuclear (IEN), foi solubilizado em $\mathrm{HNO}_{3}$ concentrado (MERCK). As duas soluções foram misturadas em quantidades estequiométricas, proporção molar de $80 \%$ de Ce (IV) e $20 \%$ de Sm (III), a solução resultante apresentou $\mathrm{pH}<1$. A seguir, foi feito o ajuste do $\mathrm{pH}$, com uma solução de $\mathrm{NH}_{4} \mathrm{OH}$ (MERCK), sob agitação 
constante à temperatura ambiente. A solução com $\mathrm{pH}$ ajustado $(\mathrm{pH}=3,0)$ foi adicionada, gota a gota, sobre uma solução de $\left(\mathrm{NH}_{4}\right)_{2} \mathrm{CO}_{3}$ (VETEC), com pH $=10$ e mantida sob agitação na temperatura de $70{ }^{\circ} \mathrm{C}$. Verificou-se a formação de uma suspensão que foi mantida inicialmente à temperatura $70{ }^{\circ} \mathrm{C}$ por duas horas, sob constante agitação, e a seguir na temperatura ambiente por mais duas horas, apresentando no final $\mathrm{pH}$ entre 8,0 e 9,0. No envelhecimento a suspensão foi deixada em repouso à temperatura ambiente, por 24 horas. $\mathrm{O}$ sólido decantado foi centrifugado e lavado, até apresentar nas águas de lavagens o $\mathrm{pH}$ próximo de 7,0. O gel obtido foi seco em estufa, a $50{ }^{\circ} \mathrm{C}$ por 20 horas e macerado em almofariz de Agatha, utilizando-se acetona como agente dispersante. Ao final desse procedimento foi obtido um pó de coloração amarelo-acastanhado (SDC/50). O material SDC/50 foi calcinado, em forno tipo mufla, em diferentes temperaturas, entre 100$1200^{\circ} \mathrm{C}$, por duas horas (amostras SDC/100 a SDC/1200).

\subsection{Obtenção de nanopartículas óxido de níquel ( $\mathrm{NiO}$ e e óxido de níquel dopado com cobalto (CoNiO).}

As nanopartículas de óxido de níquel $(\mathrm{NiO})$ e de óxido de níquel dopado com $10 \%$ cobalto $(\mathrm{CoNiO})$ foram sintetizadas pelo método sol-gel em presença de amido, que permite a obtenção de óxidos mistos homogêneos e com elevada área superficial específica [31-34]. Foram adicionados 2,0 g de amido a $20 \mathrm{~mL}$ de uma solução aquosa contendo $8,56 \mathrm{~g}$ de nitrato de níquel hexa-hidratado $\left[\mathrm{Ni}\left(\mathrm{NO}_{3}\right)_{2} \cdot 6 \mathrm{H}_{2} \mathrm{O}\right]$ (VETEC). Essa mistura foi levada a um banho ultrassônico e mantida numa temperatura entre 60 e $65^{\circ} \mathrm{C}$, por 3 horas, para a formação do gel. A secagem do gel foi realizada na temperatura de $50{ }^{\circ} \mathrm{C}$ por sete dias. $\mathrm{O}$ xerogel formado foi calcinado a $200{ }^{\circ} \mathrm{C}$ por 10 horas, para a total liberação dos produtos de decomposição do amido, observando-se significativa expansão do material. O material obtido foi desaglomerado num almofariz de Agatha, utilizando-se acetona como dispersante, obtendo-se um pó homogêneo de coloração verde claro. O pó foi calcinado ao ar, em forno tipo mufla na temperatura de $400{ }^{\circ} \mathrm{C}$, por quatro horas $(\mathrm{NiO} / 400)$, e desaglomerado em almofariz de Agatha, apresentando coloração verde musgo. Para o preparo das nanopartículas de óxido de níquel dopado com $10 \%$ cobalto $(\mathrm{CoNiO})$ foram utilizados os nitratos hexahidratados de níquel $\left[\mathrm{Ni}\left(\mathrm{NO}_{3}\right)_{2} \cdot 6 \mathrm{H}_{2} \mathrm{O}\right]$ e de cobalto $\left[\mathrm{Co}\left(\mathrm{NO}_{3}\right)_{2} \cdot 6 \mathrm{H}_{2} \mathrm{O}\right]$ (VETEC), na proporção molar de 9:1, respectivamente, seguindo o mesmo procedimento descrito na síntese do $\mathrm{NiO} / 400$. O pó calcinado $(\mathrm{CoNiO} / 400)$ apresentou coloração cinza escuro.

\subsection{Preparo de pastilhas de SDC pura e da SDC em presença dos óxidos de níquel.}

Para obtenção das pastilhas foi utilizada cerca de $1,00 \mathrm{~g}$ de amostra. Na pastilha de SDC pura foi utilizada a SDC calcinada a $600^{\circ} \mathrm{C}$ por 2 horas (SDC/600), este material foi escolhido com base em resultados de IV que indicaram a quase total eliminação de grupos $\mathrm{OH}$ e carbonato do material, após este tratamento térmico [31]. Nas pastilhas de SDC com os óxidos de níquel (NiO/SDC e CoNiO/SDC) foram utilizadas misturas de $53 \%$ $(\mathrm{m} / \mathrm{m})$ de SDC e $47 \%(\mathrm{~m} / \mathrm{m})$ de óxido de níquel $(\mathrm{NiO} / 400)$ ou óxido de níquel dopado com cobalto (CoNiO/400). O material foi colocado num pastilhador, com diametro interno de $12,95 \mathrm{~mm}$, sendo prensado mecanicamente por 2 minutos sob pressão uniaxial de 10 toneladas, na temperatura ambiente e em presença de ar. As pastilhas foram sinterizadas a $1200{ }^{\circ} \mathrm{C}$, ao ar por 5 horas, seguindo o procedimento descrito na literatura para estudos semelhantes $[10, \underline{20}, \underline{35}]$. Sendo que, foi utilizado um forno programavél, com três patamares de temperatura, sendo de $200{ }^{\circ} \mathrm{C}$ por 50 minutos, de $400{ }^{\circ} \mathrm{C}$ por 30 minutos, correspondentes a um pré-tratamento, e de $1200{ }^{\circ} \mathrm{C}$ por 300 minutos, referente a sinterização. As taxas de aquecimento, antecedentes a cada patamar, foram de $4 \% \mathrm{~min}, 6 \% \mathrm{~min}$ e $2 \% \mathrm{~min}$, respectivamente. Essas condições foram determinadas em trabalhos anteriores $[\underline{31}, \underline{36}, \underline{37}]$, sendo que, o principal critério foi o de utilizar os mesmos patamares empregados na preparação de cerâmicas com porosidade controlada, as quais são obtidas pela decomposição térmica de um formador de poros, por exemplo o amido [흐- $\underline{38}$ ]. As pastilhas mistas, de SDC com os óxidos de níquel, foram preparadas para serem posteriormente utilizadas na confecção dos cermets, através da redução dos óxidos em um ambiente redutor semelhante ao de funcionamento da pilha a combustível do tipo PaCOS [프, 24, $\underline{35}, \underline{38}]$.

\subsection{Técnicas de caracterização}

$\mathrm{Na}$ Espectroscopia no Infravermelho (IV) foi utilizado um espectrofotômetro de infravermelho (NICOLET MAGNA - IR 760), com resolução $4 \mathrm{~cm}^{-1}$ e detector DTGS-KBr. As amostras foram preparadas em pastilhas de $\mathrm{KBr}$. Os espectros foram obtidos na região de 4000 a $400 \mathrm{~cm}^{-1}$, com 32 acumulações.

A Análise Térmica (TG/DTA) foi realizada num equipamento simultâneo de TG e DTA (DTG-60, SHIMADZU CORP), utilizando como material de referência, a alumina. Os termogramas foram obtidos de 20 a $900^{\circ} \mathrm{C}$, sob atmosfera de argônio, com taxa de aquecimento igual a $10^{\circ} \mathrm{C}$. $\min ^{-1}$.

Na Difração de Raios X (DRX), método pó, foi utilizado um difratômetro RIGAKU, modelo Minefex, com radiação $\mathrm{CuK} \alpha\left(\lambda=1,5418 \mathrm{~A}^{\circ}\right)$, filtrada por $\mathrm{Ni}$, com tensão de $30 \mathrm{Kv}$ e corrente de $15 \mathrm{~mA}$. Para confir- 
mar a estrutura cúbica, avaliar a pureza e calcular o tamanho médio de cristalito das nanopartículas de SDC, $\mathrm{NiO}$ e $\mathrm{CoNiO}$ foi utilizado $2 \theta$ de $5^{\circ} \leq 2 \theta \leq 70^{\circ}$, método contínuo, com aquisição a cada $0,02^{\circ}$, recebendo para essa condição experimental o código $\mathrm{DRX}_{1}$. O tamanho de cristalito dos pós foi calculado a partir do difratograma utilizando a equação de Scherrer $[\underline{1}, \underline{13}]$. Para o cálculo do parâmetro de cela foi utilizado $2 \theta$ de $25^{\circ} \leq$ $2 \theta \leq 100^{\circ}$, passo de $0,03^{\circ}$ e tempo de contagem de 3 segundos, recebendo o código $\mathrm{DRX}_{2}$. Os difratogramas experimentais foram comparados com difratogramas extraídos da Base de Dados Crystmet do periódico CAPES e denominados $\mathrm{CeO}_{2}$ /padrão (ID 36553), $\mathrm{Sm}_{2} \mathrm{O}_{3} /$ padrão (ID 32365), SDC/padrão (ID 498235), NiO/padrão (ID 31936) e do CoO/padrão (ID 27308).

A Microscopia Eletrônica de Transmissão (TEM) foi realizada utilizando-se um Microscópio Eletrônico de Transmissão Jeol (JEM 1200EXII). A amostra foi dispersa em etanol com auxílio de um banho de ultrassom e colocada num disco feito de cobre. Após secagem, a temperatura ambiente, o disco foi colocado no porta amostra do aparelho para a análise.

Os espectros Raman foram obtidos em um Espectrômetro da Jobin Yvon Horiba (LABRAW HR 800 UV) com detector $\mathrm{CCD}$ refrigerado com nitrogênio líquido, equipado com uma $\mathrm{CCD}$ de $\mathrm{T}=-70^{\circ} \mathrm{C}$, acoplado a um microscopio óptico Olympus, modelo BH-2. Para a excitação dos espectros foi utilizado um laser de He-Ne de $\lambda=632,81 \mathrm{~nm}$ (Spectra Physics, modelo 127). Os espectros Raman foram obtidos na região de 800 a $100 \mathrm{~cm}^{-1}$, com 2 acumulações, com resolução de $1 \mu \mathrm{m}^{3}$, objetiva 100X, spot de $50 \mu \mathrm{m}$.

A densidade das pastilhas sinterizadas foi medida pela técnica de picometria, sendo utilizado um picnômetro de 35,0 mL (Vidrolabor) e uma balança de precisão com quatro casas decimais (BIOPRECISA, modelo FA2104N).

\section{RESULTADOS E DISCUSSÃO}

No estudo de sinterização foi utilizada a SDC/600, uma vez que, amostras calcinadas a uma temperatura superior a $600{ }^{\circ} \mathrm{C}$ apresentam uma perda de massa pouco significativa, identificada por Análise Térmica (TG/DTA), e a ausência de grupos $\mathrm{OH}$ e carbonatos, evidenciada por Espectroscopia no Infravermelho [31]. Essas espécies químicas estão presentes em calcinações realizadas em temperaturas menores do que $600{ }^{\circ} \mathrm{C} \mathrm{e}$ poderiam influenciar no processo de sinterização [31].

No DRX da SDC/600, Figura 1a, observam-se picos de difração bem definidos e típicos da estrutura tipo fluorita da SDC, sendo que o parâmetro de cela $(\boldsymbol{a})$ calculado foi de $0,5434 \mathrm{~nm}$, utilizando-se a condição experimental $\mathrm{DRX}_{2}$ e o programa de refinamento Eracel. O tamanho médio de cristalito, calculado pela Fórmula de Scherrer, foi de $9 \mathrm{~nm}$, este valor é consistente com o resultado de Microscopia Eletrônica de Transmissão (TEM), apresentada na Figura 1b, onde são observados agregados de nanopartículas, as quais apresentam tamanhos menores do que $20 \mathrm{~nm}$.

(a)

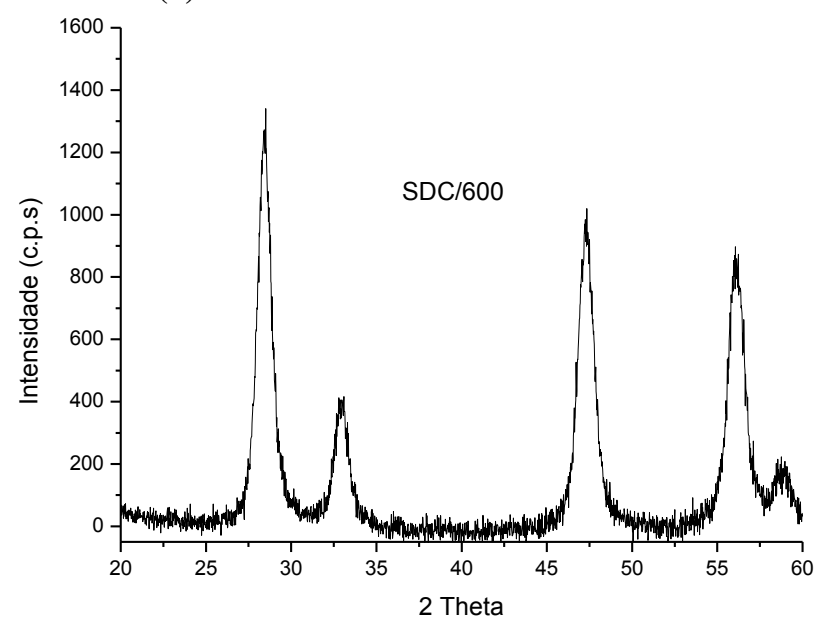

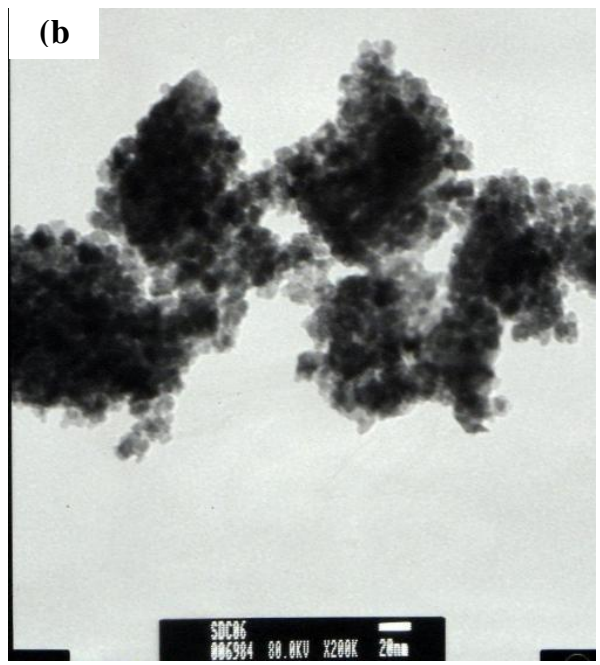

Figura 1: Material SDC/600: (a) difratograma e (b) TEM.

Devido à alta temperatura de sinterização $\left(1200^{\circ} \mathrm{C}\right)$ foi analisado também o difratograma da SDC calcinada na mesma temperatura (SDC/1200), Figura 2. Ao comparar o difratograma da SDC/1200 com o da SDC/600 verifica-se um afinamento dos picos de difração com o aumento da temperatura, indicando a influ- 
ência do tratamento térmico no aumento do tamanho de cristalito, que passou para $76 \mathrm{~nm}$, de acordo fórmula de Scherrer [1]. Observa-se nos difratogramas das amostras SDC/600 e SDC/1200 a formação da fase pura de SDC $\left(\mathrm{Ce}_{0,8} \mathrm{Sm}_{0,2} \mathrm{O}_{1,9}\right)$, com ausência de picos de difração relacionados ao $\mathrm{Sm}_{2} \mathrm{O}_{3} /$ padrão. No caso da SDC/1200 os picos são estreitos, o que comprova a boa cristalinidade da amostra, Figura 2. Com as indexações dos valores de $2 \theta$ experimentais, utilizando a Lei de $\operatorname{Bragg}(n \lambda=2 \operatorname{dsen} \theta)$, foram calculadas as distâncias interplanares experimentais $\left(\mathrm{d}_{\mathrm{hkl}}\right)$ e comparadas com os $\mathrm{d}_{\mathrm{hkl}}$ do difratograma da SDC/padrão (Tabela 1). Foi observada similaridade nos perfis de cristalinidade da SDC/1200 com a SDC/padrão, em relação tanto às posições quanto às intensidades relativas entre eles, confirmando assim a estrutura cúbica tipo fluorita da SDC/1200. Através da indexação do difratograma experimental da SDC/1200, foi calculado o parâmetro de cela $(\boldsymbol{a})$ de $0,5436 \mathrm{~nm}$, muito próximo do parâmetro de cela da SDC/padrão de $0,5437 \mathrm{~nm}$, comprovando a dopagem de $20 \%$ mol de samário na rede cristalina $[\underline{1}, \underline{10}, \underline{23}, \underline{30}]$.

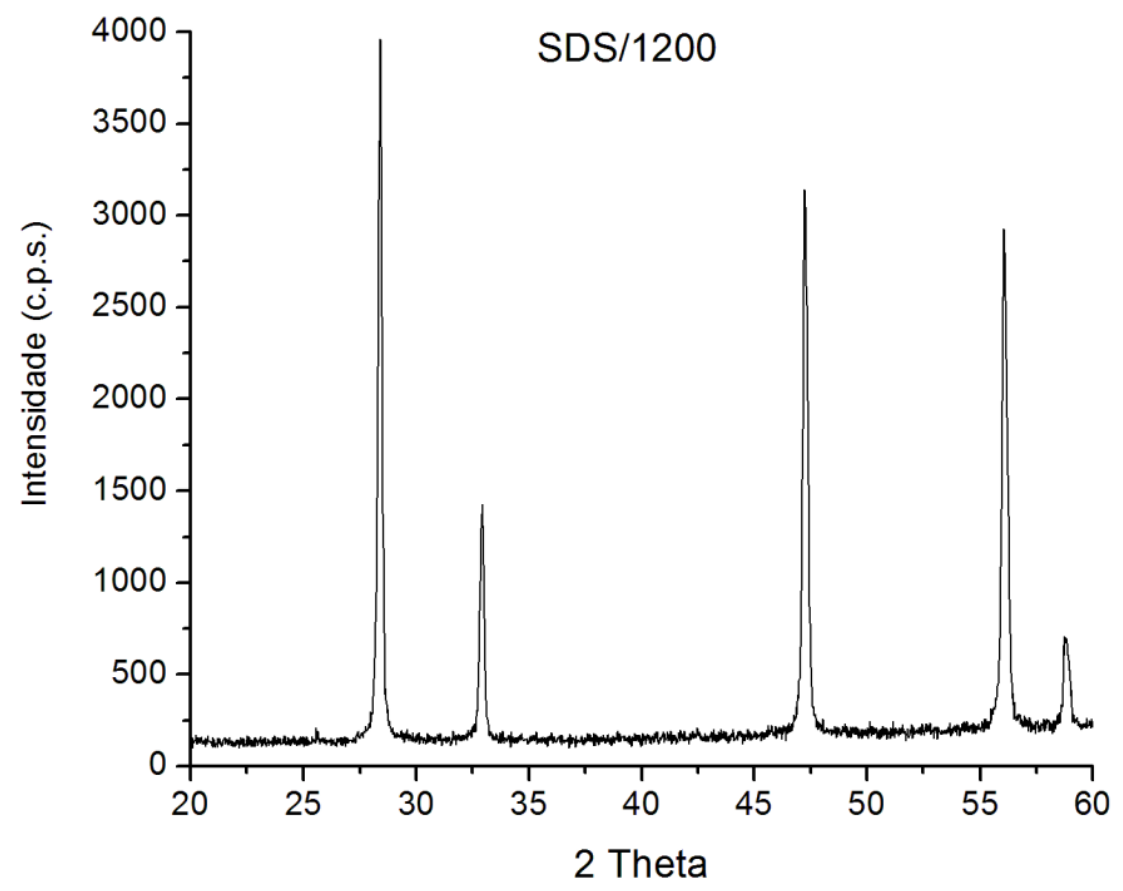

Figura 2: Difratograma da SDC/1200.

Tabela 1: Comparação entre os dados de DRX da SDC/1200 e da SDC/padrão.

\begin{tabular}{|c|c|c|c|c|c|}
\hline \multicolumn{2}{|c|}{ SDC/padrão } & \multicolumn{2}{|c|}{ SDC/1200 } & \multicolumn{2}{|c|}{ Indexações } \\
\hline $\begin{array}{l}2 \theta \\
\left({ }^{\circ}\right)\end{array}$ & $\begin{array}{c}\mathbf{d}_{\mathbf{h k l}} \\
(\mathbf{n m})\end{array}$ & $2 \theta\left({ }^{0}\right)$ & $\begin{array}{c}\mathbf{d}_{\mathrm{hkl}} \\
(\mathbf{n m})\end{array}$ & h k l & I \\
\hline 28,433 & 0,3134 & 28,520 & 0,3130 & 111 & 100 \\
\hline 32,947 & 0,2713 & 33,040 & 0,2711 & 200 & 36 \\
\hline 47,286 & 0,1921 & 47,380 & 0,1919 & 220 & 96 \\
\hline 56,102 & 0,1638 & 56,200 & 0,1637 & 311 & 17 \\
\hline
\end{tabular}

Complementando o estudo do parâmetro de cela $(\boldsymbol{a})$ a técnica Raman investigou a presença de distorções estruturais na rede do $\mathrm{CeO}_{2}$, provocadas pela dopagem de $\mathrm{Sm}^{3+}$. Nos espectros Raman (Figura 3a-b) da amostra de SDC calcinada a $600{ }^{\circ} \mathrm{C}(\mathrm{SDC} / 600)$ e da pastilha de SDC/600 sinterizada a $1200{ }^{\circ} \mathrm{C}$ (SDC/600/1200), verifica-se uma banda de alta intensidade em $462 \mathrm{~cm}^{-1} \mathrm{e}^{4} 46 \mathrm{~cm}^{-1}$, respectivamente, atribuída ao modo vibracional de simetria $\mathrm{T}_{2 \mathrm{~g}}$ característico da estrutura cúbica tipo fluorita do $\mathrm{CeO}_{2}$ [10]. Para a SDC/600/1200 se observa um pequeno deslocamento dessa banda para maiores números de onda, o qual pode ser atribuído à pequena contração na rede observada para a amostra calcinada a $1200^{\circ} \mathrm{C}(\mathrm{SDC} / 1200)$. Este resultado indica que não ocorreu redução dos íons $\mathrm{Ce}^{4+}$ durante o processo de sinterização, para a amostra SDC/600/1200 [39]. Nos espectros, também são observadas bandas largas e de baixa intensidade, entre 510 e 
$650 \mathrm{~cm}^{-1}$, relacionadas a vacâncias de oxigênio na rede que mantém a neutralidade de cargas na substituição de íons $\mathrm{Ce}^{4+}$ por $\mathrm{Sm}^{3+}[\underline{10}, \underline{39}-\underline{41}]$. As bandas, de baixa intensidade, observadas abaixo de $400 \mathrm{~cm}^{-1}$ podem ser atribuídas a modos Raman de segunda ordem característicos do $\mathrm{CeO}_{2}$ com estrutura cúbica tipo fluorita [42]. Estes resultados comprovam a dopagem do $\mathrm{CeO}_{2} \mathrm{com} \mathrm{Sm}^{3+}$ nos materiais preparados pelo método do percussor, desenvolvido neste estudo, sendo a estrutura cúbica tipo fluorita preservada no processo de sinterização, para o caso da pastilha SDC/600/1200. Esta baixa temperatura de sinterização evita a redução do íon $\mathrm{Ce}^{+4}$ a $\mathrm{Ce}^{+3}$, como indicam as técnicas de caracterização utilizadas neste estudo. Este resultado é bastante significativo, uma vez que, esta redução pode produzir micro trincas, o que deteriora as propriedades mecânicas das cerâmicas [요밀.
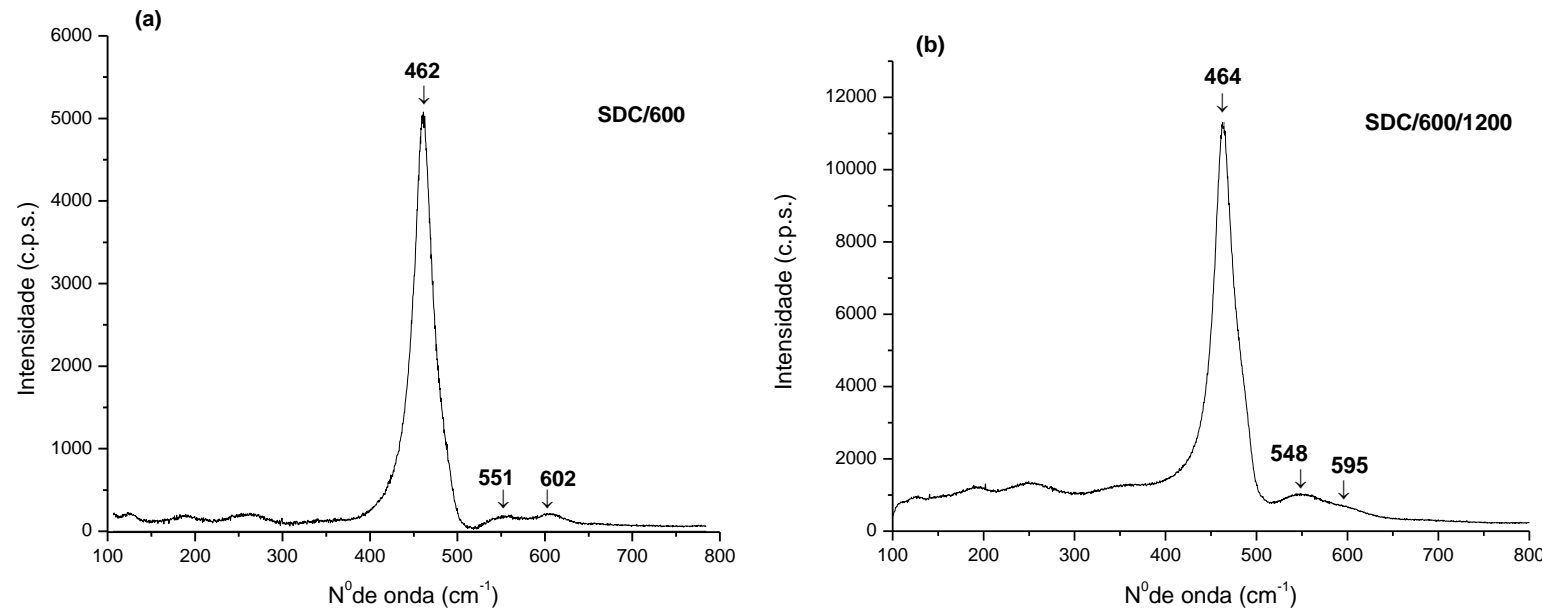

Figura 3: Espectros Raman dos materiais: (a) SDC/600 e (b) SDC/600/1200

Os difratogramas experimentais do NiO/400 e CoNiO/400 (Figura 4), foram comparados com os difratogramas do $\mathrm{NiO} /$ padrão e do $\mathrm{CoO} /$ padrão (Tabela 2a-b), comprovando a formação de nanopartículas de $\mathrm{NiO}$ e de $\mathrm{CoNiO}$, respectivamente, com estrutura cúbica tipo $\mathrm{NaCl}$. Não foi verificada a formação de níquel metálico e os óxidos apresentam um tamanho médio de cristalito (Fórmula de Scherrer), de 35 e 36 nm, respectivamente, para as nanopartículas de $\mathrm{NiO}$ e CoNiO. Para a amostra CoNiO, a introdução de cobalto, na rede cristalina cúbica do $\mathrm{NiO}$, é evidenciada pelo deslocamento dos picos do DRX, em direção a ângulos menores, apresentando um parâmetro de cela (a) intermediário aos do NiO/padrão e $\mathrm{CoO} /$ padrão (Tabela 3).

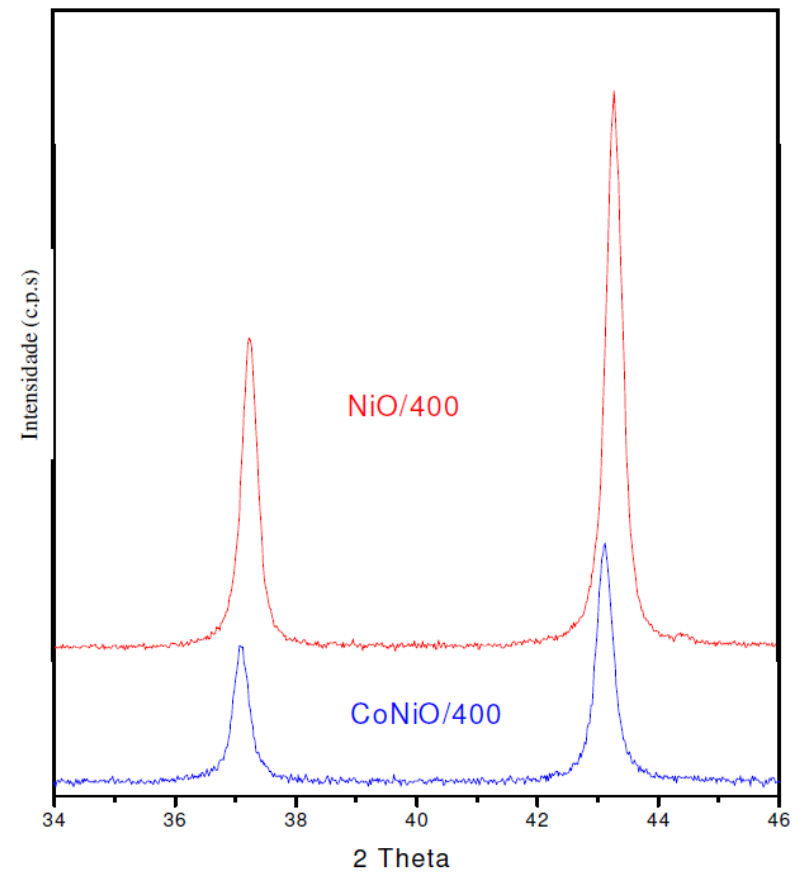

Figura 4: Difratogramas do $\mathrm{NiO} / 400$ e $\mathrm{CoNiO} / 400$. 
Tabela 2(a): Dados do DRX do NiO/400 e do NiO/padrão.

\begin{tabular}{|c|c|c|c|c|c|}
\hline \multicolumn{2}{|c|}{ NiO/padrão } & \multicolumn{2}{c|}{ NiO/400 } & \multicolumn{2}{c|}{ Indexações } \\
\hline $\begin{array}{c}\mathbf{2} \boldsymbol{\theta} \\
\mathbf{(}^{\mathbf{o}}\end{array}$ & $\begin{array}{c}\mathbf{d}_{\mathbf{h k l}} \\
(\mathbf{n m})\end{array}$ & $\begin{array}{c}\mathbf{2} \boldsymbol{\theta} \\
\left.\mathbf{(}^{\mathbf{}}\right)\end{array}$ & $\begin{array}{c}\mathbf{d}_{\mathbf{h k l}} \\
(\mathbf{n m})\end{array}$ & $\mathbf{h} \mathbf{k} \mathbf{~}$ & $\mathbf{I}$ \\
\hline 37,350 & 0,2408 & 37,240 & 0,2414 & 111 & 60 \\
\hline 43,399 & 0,2085 & 43,280 & 0,2090 & 200 & 100 \\
\hline
\end{tabular}

Tabela 2(b): Dados do DRX do CoNiO/400 e do CoNiO/padrão.

\begin{tabular}{|c|c|c|c|c|c|}
\hline \multicolumn{2}{|c|}{ CoO/padrão } & \multicolumn{2}{c|}{ CoNiO/400 } & \multicolumn{2}{c|}{ Indexações } \\
\hline $\mathbf{2} \boldsymbol{\theta}$ & $\begin{array}{c}\mathbf{d}_{\text {hkl }} \\
(\mathbf{0})\end{array}$ & $\begin{array}{c}\mathbf{2} \boldsymbol{\theta} \\
(\mathbf{n m})\end{array}$ & $\begin{array}{c}\mathbf{d}_{\mathbf{h k l}}^{\mathbf{}} \\
(\mathbf{n m})\end{array}$ & $\mathbf{h ~ k ~ \mathbf { l }}$ & $\mathbf{I}$ \\
\hline 36,892 & 0,2408 & 37,080 & 0,2424 & 111 & 60 \\
\hline 42,859 & 0,2085 & 43,120 & 0,2098 & 200 & 100 \\
\hline
\end{tabular}

Na Figura 5, os difratogramas da SDC/600/1200 e NiO/SDC/600/1200 indicam que a estrutura tipo fluorita da SDC é preservada em todas as pastilhas, com e sem adição dos óxidos de níquel. Pode-se observar ainda, que não são observadas alterações na posição dos picos, indicando que não ocorreu incorporação, significativa, de níquel ou cobalto na estrutura da SDC, durante a sinterização das pastilhas $1200^{\circ} \mathrm{C}$.

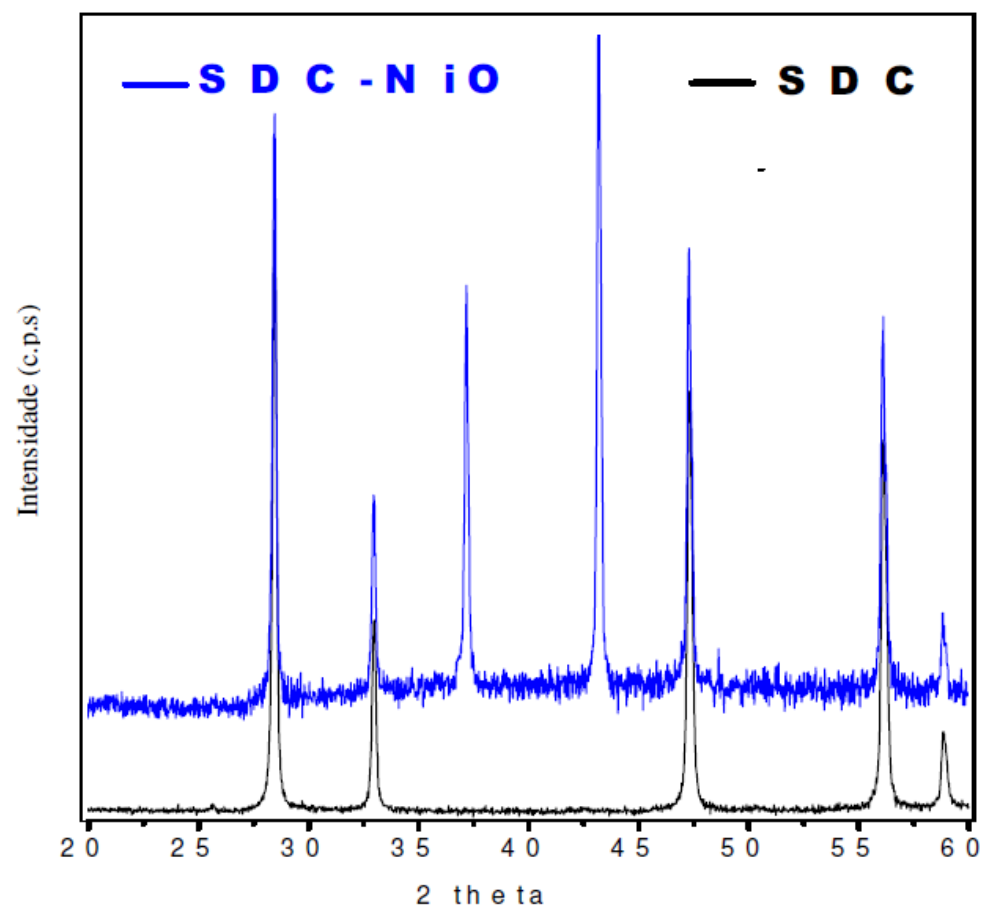

Figura 5: Difratogramas das amostras SDC/600/1200 e NiO/SDC/600/1200, sinterizadas.

Tabela 3: Parâmetro de cela (a) dos óxidos de níquel.

\begin{tabular}{|l|l|}
\hline Amostras & $\mathbf{a}(\mathbf{n m})$ \\
\hline $\mathrm{NiO} / 400$ & 0,4180 \\
\hline $\mathrm{NiO} /$ padrão & 0,4170 \\
\hline $\mathrm{CoNiO} / 400$ & 0,4197 \\
\hline $\mathrm{CoO} /$ padrão & 0.4220 \\
\hline
\end{tabular}


Uma das propriedades mais importantes para que a SDC seja utilizada como eletrólito na preparação de componentes de pilhas a combustível do tipo PaCOS é a densidade de suas pastilhas sinterizadas, que deve ser igual ou superior a $90 \%$ da densidade teórica do óxido de cério. Na Tabela 4 são apresentados os resultados de \% de sinterização, os quais foram obtidos a partir das densidades das pastilhas, tomando como referência as densidades teóricas dos óxidos e de suas misturas.

Tabela 4: Dados de dimensão e percentual de sinterização das pastilhas.

\begin{tabular}{|l|c|c|}
\hline Pastilhas & \% de sinterização & Diâmetro (mm)* \\
\hline $\mathrm{SDC} / 600 / 1200$ & 83,1 & 11,87 \\
\hline $\mathrm{NiO} / \mathrm{SDC} / 600 / 1200$ & 93,7 & 11,78 \\
\hline $\mathrm{CoNiO} / \mathrm{SDC} / 600 / 1200$ & 98,6 & 11,69 \\
\hline
\end{tabular}

* Diâmetro inicial de 12,95 mm, para as pastilhas antes da sinterização.

Os dados da Tabela 4 indicam que a SDC/600/1200 apresenta uma baixa \% de sinterização (<90\%), entretanto, observa-se um aumento significativo na porcentagem de sinterização quando são adicionados os óxidos de níquel, sendo obtidas pastilhas com porcentuais de sinterização superiores a 90\%. Estes resultados demonstram que os óxidos de níquel atuam como agentes densificadores. Verifica-se ainda que a pastilha de $\mathrm{CoNiO/SDC/600/1200} \mathrm{apresentou} \mathrm{um} \mathrm{percentual} \mathrm{de} \mathrm{sinterização} \mathrm{significativamente} \mathrm{maior} \mathrm{do} \mathrm{que} \mathrm{as} \mathrm{demais.}$ Cabe salientar que estes porcentuais de sinterização foram obtidos na temperatura de $1200{ }^{\circ} \mathrm{C}$, consideravelmente inferior às utilizadas na literatura que estão por volta de $1500^{\circ} \mathrm{C}[\underline{8}-\underline{13}]$.

\section{CONCLUSÕES}

Através dos resultados de caracterização foi comprovada a formação de pós cerâmicos homogêneos com $20 \%$ mol de samário incorporado na rede do óxido de cério $\left(\mathrm{Ce}_{0,8} \mathrm{Sm}_{0,2} \mathrm{O}_{1,9}\right)$. Sendo que, suas partículas apresentam dimensões nanométricas. Na sinterização a $1200^{\circ} \mathrm{C}$, por $5 \mathrm{~h}$, foram obtidas pastilhas com densidades relativas de 83,4 \% para a SDC pura e valores acima de $90 \%$ para a SDC com os óxidos de níquel. Ficou demonstrado que a presença de $\mathrm{NiO}$ ou do óxido de níquel dopado com $10 \%$ de cobalto $(\mathrm{CoNiO})$ aumenta o grau de sinterização das pastilhas de SDC, sem uma incorporação significativa de íons níquel ou cobalto na rede cristalina da SDC. Os resultados apresentados comprovam que nanopartículas de SDC produzidas através do método do precussor possibilitam a obtenção de cerâmicas com boa densificação, o que é um dos prérequisitos para que um material possa ser utilizado na preparação de componentes para pilhas a combustível do tipo PaCOS.

\section{AGRADECIMENTOS}

IMA/UFRJ, CNPq/CT-Energ, FAPERJ e CAPES. Ao Departamento de Química da UFPR, pela análise de microscopia eletrônica de transmissão (TEM).

\section{BIBLIOGRAFIA}

[1] MALTA, L. F. B., "Síntese e caracterização de céria dopada e codopada com íons cálcio e estrôncio para a aplicação como eletrólito sólido em pilhas a combustível”, Tese de D.Sc., IQ/UFRJ, Rio de Janeiro, RJ , Brasil, 2002.

[2] AMARAL, A. A., MATOS, F. F., BENEDICTO, J. P., et al., "Eficiência Teórica de Pilhas a Combustível do tipo PaCOS”, Matéria (Rio J.), v. 12, n. 1, pp. 54-64, Jan. 2007.

[3] GARRIDO, F. M. S., MEDEIROS, R. F., NOGUEIRA N. O. B., et al., "Síntese de óxidos mistos Si$\mathrm{O}_{2} / \mathrm{Mn}_{\mathrm{x}} \mathrm{O}_{\text {y }}$ para aplicação na reação de redução de $\mathrm{O}_{2}$ ”, Matéria (Rio J.), v. 18, n. 2, pp. 1294-1305, Abr. 2013.

[4] CASSÚS, E. P., MACHADO, S. P., GARRIDO, F. M. S., et al., "Interação de átomos leves com clusters de metais de transição", Química Nova, v. 34, n. 9, pp. 1521-1525, Set. 2011.

[5] VENÂNCIO, S. A., GUTIERRES, T. F., SARRUF, B. J. M., et al., "Oxidação direta do etanol no anodo de PaCOS", Matéria (Rio J.), v. 13, n. 3, pp. 560-568, Jul. 2008

[6] SARRUF, B. J. M., CIDADE, R. A., BRAGA, V. P., et al., "Reconstrução digital de volume de eletrodo de PaCOS para cálculo de porosidade e tortuosidade”, Matéria (Rio J.), v. 18, n. 1, pp. 67-74, Jan. 2013. 
[7] AMADO, R. S., MALTA, L. F. B., GARRIDO, F. M. S., et al., "Pilhas a combustível de óxido sólido: materiais, componentes e configurações", Química Nova, v. 30, n.1, pp. 189-197, Jan. 2007.

[8] CROCHEMORE, G. B., ANTUNES, F. C., SOUZA, D. P. F., "Propriedades elétricas e microestrutural de Céria dopada com $\mathrm{Gd}^{+3} \mathrm{e} \mathrm{Y}^{+3}$ para aplicação como eletrólitos em pilhas a combustível", Matéria (Rio J.), v. 13, n. 3, pp. 495-511, Jul. 2008.

[9] PRASAD, D. H., SON, J. W., KIM, B. K., et al., "Synthesis of nano-crystalline $\mathrm{Ce}_{0.9} \mathrm{Gd}_{0.1} \mathrm{O}_{1.95}$ electrolyte by novel sol-gel thermolysis process for IT-SOFCs", Journal of the European Ceramic Society, v. 28, pp. 3107-3112, 2008.

[10] SIQUEIRA JÚNIOR, J.M., MALTA, L.F.B., GARRIDO, F.M.S., et al., "Raman and Rietveld structural characterization of sintered alkaline earth doped ceria", Materials Chemistry and Physics, v. 135, n. 2-3, pp. 957-964, Aug. 2012.

[11] PATAKANGAS, J., MA, Y., JING, Y., LUND, P., "Review and analysis of characterization methods and ionic conductivities for low-temperature solid oxide fuel cells (LT-SOFC)", Journal of Power Sources, v. 263, pp. 315-331, 2014.

[12] PRASAD, D. H., LEE, J. H., LEE, H. W., et al., "Correlation between the powder properties and sintering behaviors of nano-crystalline gadolinium-doped ceria", Journal of Ceramic Processing Research, v. 11, n. 5, pp. 523-526, Set. 2010.

[13] VILLAS-BÔAS, L. A., SOUZA, D. P. F., "Efeito da adição de óxido de cobalto na sinterização e propriedades elétricas da cerâmica $\mathrm{Ce}_{0,8} \mathrm{Gd}_{0,2} \mathrm{O}_{1,9}$ obtida a partir nanopós", Cerâmica, v. 60, n. 354, pp. 285-290, Junho 2014 .

[14] AKIMOTO, W., FUJIMOTO, T., SAITO, M., et al., "Ni-Fe/Sm-doped $\mathrm{CeO}_{2}$ anode for ammonia-fueled solid oxide fuel cells", Solid State Ionics, v. 256, pp. 1-4, Mar. 2014.

[15] SKALAR, T., ZUPAN, K., MARINSEK, M., et al., "Microstructure evaluation of Ni-SDC synthesized with an innovative method and Ni-SDC/SDC bi-layer construction", Journal of the European Ceramic Society, v. 34, pp. 347-354, 2014.

[16] MELCHIONNA, M., FORNASIERO, P., "The role of ceria-based nanostructured materials in energy applications", Materials Today, v. 17, n. 7, pp. 349-357, Sep. 2014.

[17] WANG, Z., LI, Y., SCHWANK, J. W., "Evaluation of Ni/SDC as anode material for dry $\mathrm{CH}_{4}$ fueled Solid Oxide Fuel Cells", Journal of Power Sources, v. 248, pp. 239-245, 2014.

[18] MUCCILlO E. N. S., TADOKORO, S. K., "Microestrutura e condutividade elétrica em $\mathrm{Ce}_{0,85} \mathrm{Y}_{0,15-\mathrm{x}} \mathrm{R}_{\mathrm{x}} \mathrm{O}_{2-\delta}(\mathrm{R}=\mathrm{Pr}, \mathrm{Tb})$ ", Cerâmica, v. 53, pp. 89-98, 2007.

[19] MUCCILLO, E. N. S., PORFÍRIO, T. C.,TADOKORO, S. K., et al., "Propriedades físicas do óxido de cério preparado por técnica de solução e a condutividade elétrica em função da pressão parcial de oxigênio em cerâmicas sinterizadas", Cerâmica, v. 51, n. 318, pp.157-162, Apr. 2005.

[20] LI, H., XIA, C., ZHU, M., ZHOU, Z., et al., "Reactive $\mathrm{Ce}_{0.8} \mathrm{Sm}_{0.2} \mathrm{O}_{1.9}$ powder synthesized by carbonate coprecipitation: Sintering and electrical characteristics", Acta Materialia, v. 54, pp. 721-727, 2006.

[21] HUANG, W., SHUK, P., GREENBLATT, M., "Properties of sol-gel prepared $\mathrm{Ce}_{1-\mathrm{x}} \mathrm{Sm}_{\mathrm{x}} \mathrm{O}_{2-x / 2}$ solid electrolytes", Solid State Ionics, v. 100, pp. 23-27, 1997.

[22] MALTA, L. F. B., OGASAWARA, T., "Degradation of some ceria electrolytes under hydrogen contact nearby anode in solid oxide fuel cells (SOFCs)", Materials Research, v. 7, n. 1, p. 209-213, March 2004.

[23] MALTA, L. F. B., CAFFFARENA, V. R., MEDEIROS, M. E., et al., "TA of non-stoichiometric ceria obtained via hydrothermal synthesis", Journal of Thermal Analysis and Calorimetry, v. 75, n. 3, pp. 901-910, 2004.

[24] SILVA, M. A., ALENCAR, M. G. F., FIÚZA, R. P., et al., "Preparação e Avaliação de Célula a Combustível do Tipo PaCOS Unitária com Ânodo a base de Níquel e Cobalto", Matéria (Rio J.), v. 12, pp. 72-85, Jan. 2007.

[25] COSTA, L. O. O., SILVA, A. M., NORONHA, F. B., et al., "The study of the performance of Ni supported on gadolinium doped ceria SOFC anode on the steam reforming of ethanol", International Journal of Hydrogen Energy, v. 37, pp. 5930-5939, 2012.

[26] LEE, J. G., PARK, M. G., HYUN, S. H., et al., "Nano-composite $\mathrm{Ni}-\mathrm{Gd}_{0.1} \mathrm{Ce}_{0.9} \mathrm{O}_{1.95}$ anode functional layer for low temperature solid oxide fuel cells", Electrochimica Acta, v. 129, pp. 100-106, 2014. 
[27] AUGUSTO, B. L., NORONHA, F. B., FONSECA, F. C., et al., "Nickel/gadolinium-doped ceria anode for direct ethanol solid oxide fuel cell", International Journal of Hydrogen Energy, v. 39, pp. 11196-11209, 2014.

[28] REIS, S. L., MUCCILLO, E. N. S., "Densificação, tamanho de grãos e condutividade elétrica da cériasamária", Cerâmica, v. 57, n. 343, p. 371-380, Set. 2011.

[29] ARAUJO, H. E., SOUZA, D. P. F., "Condutividade elétrica de $\mathrm{CeO}_{2}-10 \mathrm{~mol} \% \mathrm{Gd}_{2} \mathrm{O}_{3}-\mathrm{x} \mathrm{mol} \% \mathrm{Sm}_{2} \mathrm{O}_{3}$ $(0<\mathrm{x}<2)$ ", Cerâmica, v. 59, n. 350, p. 235-241, Jun. 2013.

[30] REY, J. F. Q., MUCCILLO, E. N. S., "Parâmetros de rede em condutores de íons oxigênio com estrutura fluorita: estudo da solução sólida céria-ítria", Cerâmica, Set 2002, v. 48, n. 307, pp. 157-162, Set. 2002.

[31] CALDAS, F. R. R., Síntese, caracterização e sinterização de nanopartículas de óxido de cério dopado com samário (SDC) para aplicação em pilhas a combustivel, Dissertação de Mestrado em Química Inorgânica, IQ/UFRJ, Rio de Janeiro, RJ, Brasil, 2010.

[32] PIEDADE, D. M., SIQUEIRA-JÚNIOR, J. M., GARRIDO, F. M. S., "Obtenção de nanopartículas de óxido de níquel dispersas em matriz orgânica amorfa", In: 31 $1^{\underline{a}}$ Reunião Anual da Sociedade Brasileira de Química, Águas de Lindóia - SP, Brasil, 26-29 Maio 2008.

[33] TIRSOAGA, A., VISINESCU, D., JURCA, B., et al., "Eco-friendly combustion based synthesis of metal aluminates $\mathrm{MAl}_{2} \mathrm{O}_{4}(\mathrm{M}=\mathrm{Ni}, \mathrm{Co})$ ", Journal of Nanoparticle Research, v. 13, pp. 6397-6408, 2011.

[34] VISINESCU, D., JURCA, B., IANCULESCU, A., et al., "Starch - A suitable fuel in new low- temperature combustion-based synthesis of zinc aluminate oxides", Polyhedron, v. 30, pp. 2824-2831, 2011.

[35] DING, C., HASHIDA, T., "Synthesis and evaluation of $\mathrm{NiO}-\mathrm{Ce}_{0.8} \mathrm{Sm}_{0.2} \mathrm{O}_{1.9}$ nanocomposite powders for low-temperature solid oxide fuel cells", International Journal of Hydrogen Energy, v. 36, n. 9, pp. 55675573, May. 2011.

[36] FONSECA, B. T., MEDEIROS, M. E., GARRIDO, F. M. S., "Síntese e Caracterização de Catodos Porosos à Base de LSM", In: 30ª Reunião Anual da Sociedade Brasileira de Química, Águas de Lindóia - SP, Brasil, 29-31 Maio 2007.

[37] COSTA, F. P. B., MEDEIROS, M. E., GARRIDO, F. M. S., "Obtenção de catodos porosos de fases BIMEVOX para pilhas a combustível do tipo SOFC", In: $30^{\mathrm{a}}$ Reunião Anual da Sociedade Brasileira de Química, Águas de Lindóia - SP, Brasil, 29-31 Maio 2007.

[38] TAILLADES, G., BATOCCHI, P., ESSOUMHI, A., et al., "Engineering of porosity, microstructure and electrical properties of Ni-BaCe0.9Y0.1O2.95 cermet fuel cell electrodes by gelled starch porogen processing”, Microporous and Mesoporous Materials, v. 145, n. 1-3, pp. 26-31, Nov. 2011.

[39] ANANTHARAMAN, S. B., BAURI, R., "Effect of sintering atmosphere on densification, redox chemistry and conduction behavior of nanocrystalline $\mathrm{Gd}$-doped $\mathrm{CeO} 2$ electrolytes", Ceramics International, v. 39, n. 8, pp. 9421-9428, Dec. 2013.

[40] PRASAD, D. H., PARK, S. Y., JI, H.-I., H.-R. KIM, H.-R., SON, J.-W., KIM, B.-K., LEE, H.-W., LEE, J.-H, "Structural Characterization and Catalytic Activity of $\mathrm{Ce}_{0.65} \mathrm{Zr}_{0.25} \mathrm{RE}_{0.1} \mathrm{O}_{2-\delta}$ Nanocrystalline Powders Synthesized by the Glycine-Nitrate Process", Journal of Physical Chemistry C, v. 116, pp. 3467-3476, Jan. 2012.

[41] CHEN, S.-Y., CHEN, R.-J., LEE, W., "Spectromicroscopic evidence of interstitial and substitutional dopants in association with oxygen vacancies in Sm-doped ceria nanoparticles", Physical Chemistry Chemical Physics, v. 16, pp. 3274-3281, Jan. 2014.

[42] ZDRAVKOVIĆ, J., SIMOVIĆ, B., GOLUBOVIĆ, A., et al., "Comparative study of $\mathrm{CeO}_{2}$ nanopowders obtained by the hydrothermal method from various precursors", Ceramics International, v. 41, pp. 19701979, Mar. 2015. 